\title{
Introductory Letter
}

\author{
Cynthia Bir ${ }^{1}$
}

Published online: 19 December 2016

(C) Springer Science+Business Media Singapore 2017

It is with great honor that I have been asked to provide an introductory letter for inaugural issue of "Human Factors and Mechanical Engineering for Defense and Safety." The creation of this journal has been the result of the vision of our two Editors-in-Chief: Sebastien Roth and Alexandre Papy. They have worked to establish an international editorial board of experts in the area of defense safety. Those of us on the board, as well as others within the scientific community, applaud their efforts.

The launch of this journal provides a much-needed venue in which to disseminate our research findings. The research field related to defense safety has justifiably expanded in the last decade. Instead of pockets of research being conducted globally, there are now expansive collaborative research efforts worldwide. These efforts include everything from basic science research to end-user product testing.

This journal will help the scientific community document and share the efforts being conducted. We hope that the articles presented will inform and inspire others to build upon the current foundation. This expansion of research will not only help those on the front line in the field of defense but also society in general. There have been numerous technologies and treatments that have translated from the military trauma setting directly into our local trauma centers. This knowledge is invaluable and needs to be widely disseminated.

The "Human Factors and Mechanical Engineering for Defense and Safety" journal will allow all of these efforts to have a place in the scientific literature. Topics will include biomechanics, safety standards, behind-armor trauma, ergonomics, simulations, usability, vehicle engineering and more. All of which are being evaluated in the defense and military setting. In the past, the literature on these topics was scattered in other journals that were not quite the "right fit." This journal will provide a central platform for this highly important scientific knowledge and give researchers a place to find the most up-to-date research related to defense safety. It is our goal that research in these areas will not stagnate, but continue to grow and expand.
Cynthia Bir

cbir@usc.edu

1 Center for Trauma, Violence, \& Injury Prevention, University of Southern California, Los Angeles, CA, USA 